\title{
Ciudadanía, sufragio y propiedad en las Constituciones francesas de 1791 y 1793
}

\author{
Citizenship, suffrage and property in the French constitutions \\ of 1791 and 1793
}

Luis Sánchez Quiñones

Abogado. Doctorando UNED

luissanchezquinones@hotmail.com

doi: http://dx.doi.org/10.18543/djhr.1758

Fecha de recepción: 11.10.2019

Fecha de aceptación: 20.02.2020

Cómo citar/Citation: Sánchez Quiñones, Luis. 2020. «Ciudadanía, sufragio y propiedad en las Constituciones francesas de 1791 y 1793». Deusto Journal of Human Rights, n. 5: 99-124. doi: http://dx.doi.org/10.18543/ djhr.1758

Sumario: Introducción. 1. La regulación de la condición de elector y elegible, del derecho de sufragio y de la propiedad en el texto de las Constituciones de 1791 y 1793. 2. Ideas previas sobre ciudadanía, propiedad y sufragio. 3.La concepción opuesta de ambos textos. 3.1. La regulación en el texto constitucional de 1791 y la perspectiva de Locke y Montesquieu. 3.2. El texto constitucional de 1793. El triunfo de Mably y Rousseau. Conclusiones. Referencias bibliográficas

Resumen: En apenas tres años, la Revolución Francesa promulgó dos Constituciones en las que los derechos políticos contaron con una perspectiva radicalmente opuesta. El primero de los textos, suscrito en 1791, planteaba un derecho de sufragio radicado en la propiedad de raíces lockianas. Sin embargo, en 1793 se estableció un derecho de sufragio mucho más amplio basado en la mera condición del sujeto y obviando las referencias a la propiedad.

Palabras clave: Constitución, propiedad, ciudadanía, sufragio, igualdad.

Abstract: In just three years, the French Revolution enacted two Constitutions in which political rights received a radically different treatment. The first of these texts, signed in 1791, established a right to vote based on ownership as conceived by Locke. However, in 1793 a much broader right to vote was established based on the mere condition of the subject as an individual and disregarding any references to property.

Keywords: Constitution, property, citizenship, suffrage, equality. 


\section{Introducción}

«La Revolución francesa es una de las grandes épocas del orden social.

Aquellos que la consideran como algo accidental, no han puesto su mirada en el pasado ni en el futuro.»

(Madame de Stäel)

Tras la Revolución Francesa, la Asamblea Nacional Constituyente aprobó en agosto de 1789 la Declaración de Derechos del Hombre y del Ciudadano (Declaración de Derechos del Hombre y del Ciudadano de 1789 1877, 4-7). Posteriormente en septiembre de 1791, se aprobó un texto constitucional que instauró una Monarquía Parlamentaria (Constitución francesa de 1791 1834, 239-257).

En el año I del calendario republicano, se promulgó un nuevo texto constitucional (Constitución francesa de 1793 1834, 353-358) (junio de 1793). Dicho texto incorporó una nueva Declaración de Derechos del Hombre y del Ciudadano (Declaración de Derechos del Hombre y del Ciudadano de 1793 1877, 8-12) y que no llegaría a entrar en vigor.

A través de estas notas nos acercaremos a la configuración de la condición de ciudadano en ambos textos constitucionales que en modo alguno resultaba equivalente. Dicha condición se delimitó a través de la propiedad como medio para otorgar o denegar el derecho de sufragio que, a su vez, era la fuente de la participación política. El examen que realizaremos de dichos textos y del pensamiento político de la época nos permitirá advertir las notables diferencias existentes entre la Constitución de 1791 y la otorgada apenas dos años más tarde, y comprender las influencias ideológicas de cada uno de ellos.

Hay que señalar que la ausencia de equiparación entre los distintos estamentos sociales y el quebramiento de la ansiada igualdad que propugnaban los revolucionarios, sustentada en un criterio de propiedad y aportación a las cargas del reino, limitaron el acceso al derecho de sufragio. Esto generó una profunda desilusión tras la promulgación del texto constitucional de 1791, suscitando además fuertes críticas. Ese descontento fue el germen de las posteriores reivindicaciones que, tras la caída de la monarquía en 1792, se realizaron desde las filas jacobinas y que culminaron con el otorgamiento del sufragio universal en la Constitución de 1793.

Más allá de las diametralmente opuestas posiciones sustentadas en ambos casos, no deja de resultar evidente la estrecha relación que la condición de propietario tuvo sobre el reconocimiento de la condición 
de ciudadano y el otorgamiento de derechos políticos en el texto de $1791 \mathrm{y}$, a sensu contrario, la relativización de la propiedad como elemento definitorio en la condición de ciudadano, lo que facilitó el acceso al derecho de sufragio en la Constitución Jacobina del año I.

Las carencias del texto del año 1791, sin embargo, contaban con diversas justificaciones, fruto de la influencia del pensamiento inglés y de la propia estructura social de la que procedía la incipiente sociedad revolucionaria francesa. Esa estructura social se advirtió en la redacción del Juramento del Juego de Pelota leído por el diputado Bailly el 20 de junio de 1789 y que fue ratificado por la totalidad de la Asamblea Nacional creada al efecto, a excepción de uno de sus miembros. El juramento establecía el compromiso de otorgar una Constitución al país con el firme compromiso de no disolverse hasta entonces ${ }^{1}$.

Los asamblearios manifestaron su compromiso para defender la monarquía y el reino ya que en aquel momento todavía se consideraba inviolable la persona del rey. Pese a ello, el Juramento era la expresión de la situación política existente en la Francia de 1789 ante el fracaso que habían experimentado los Estados Generales convocados ese mismo año (Soboul 1979a, 101-104). La suscripción del documento fue el inicio del proceso constituyente que permitió la adopción por parte de la Asamblea Nacional en fecha 26 de agosto de 1789 de la Declaración de Derechos del Hombre y del Ciudadano y en septiembre de 1791 de la Constitución del mismo año.

El texto de la Declaración de Derechos fue considerado como el esquema básico del futuro estado constitucional (Tomás y Valiente 1996, 49). El citado texto no fue aislado a instancia del conde de Laly-Tollendal de la redacción del texto constitucional (Sánchez Viamonte 1956, 46). Por aquel entonces, se discutía si la Declaración contenía derechos anteriores a la redacción de la propia Constitución y a la propia ley (Sánchez Viamonte 1956, 161)² o si por el contrario

1 El texto decía: «La Asamblea Nacional, considerando que, habiendo sido llamada para establecer la Constitución del reino, obrar la regeneración del orden público y mantener los verdaderos principios de la monarquía, nada puede impedir que continúe sus deliberaciones, en cualquier lugar en que se vea forzada a residir, y que, en fin, allá donde sus miembros, se reúnan, allí está la Asamblea Nacional. Acuerdo que todos los miembros de esta Asamblea prestarán al instante el juramento de no separarse nunca y de reunirse allá dónde lo exijan las circunstancias, y hasta que la Constitución del reino sea establecida y afirmada sobre sólidas bases. Todos sus miembros, y cada uno de ellos en particular, confirmarán con su firma esta resolución inquebrantable».

2 Barnave defendía que su necesidad era absoluta: para fijar el espíritu de la legislación posterior y guiar a la obra que completaría a esa legislación. Así lo expuso en la sesión de la Asamblea de 1 de agosto de 1789. 
derivaban de ella (Sánchez Viamonte 1956, 53-56). En cualquier caso, se apostaba por un criterio más próximo a la regeneración que a la destrucción del orden anterior (Rodríguez Álvarez 1996, 206)33.

Esa integración de ambos documentos se advierte en el Preámbulo de la Constitución de 1791, en el que se declaraban como valores supremos e indiscutibles la libertad e igualdad, declarando abolidas la nobleza, dignidades del régimen feudal u organizaciones similares, en una concesión más aparente que real al Tercer Estado (Bello 1991, 72-74), ya que pese a la supresión de las dignidades nobiliarias mediante los Decretos de Agosto, no se eliminarían las barreras que limitaban el acceso a los derechos de sufragio activo y pasivo.

Dicha limitación desilusionó a las clases populares y particularmente al pueblo llano y clases no propietarias, que vieron mutar la inicial igualdad en una diferenciación por razón de la propiedad. Propiedad que, en esencia, no era más que una traslación de la división estamental heredada del Antiguo Régimen, pero suprimiendo los privilegios nobiliarios por el título de propiedad.

Tras la caída de Luis XVI y su posterior proceso se precipitaron los acontecimientos que implicaron una fractura definitiva con el Antiguo Régimen: la crisis económica, las guerras internacionales y el ascenso del movimiento social de los sans-culottes — base social del jacobinismo - sentaron la base para el ascenso definitivo al poder del partido de la Montaña (Vovelle 1981, 35-38).

La ejecución de los líderes girondinos en el verano de 1793 permitió la acción sin cortapisas de los miembros del antiguo Club Bretón y la elaboración y posterior aprobación en agosto de ese mismo año de la Declaración de Derechos del Hombre y del Ciudadano y la Constitución de 1793 (Vovelle 1981, 50). Declaración que, pese a no entrar en vigor por razón de las guerras que la República afrontaba en ese momento y al declararse el gobierno «revolucionario hasta la paz», colmaban, al menos sobre el papel, las aspiraciones no satisfechas en el texto precedente, culminando los anhelos de una participación política colectiva y generalizada de la totalidad de la población.

El objetivo del presente artículo es establecer cuál fue el marco constitucional y la relación que rigió a un concepto eminentemente abstracto como es el de ciudadanía con otro plenamente asentado en el ordenamiento jurídico-propiedad, y cómo la unión de ambos delimitó el derecho fundamental a la participación política tanto en sentido positivo — reconocimiento- como negativo —exclusión- de

3 La monarquía era el símbolo de unión entre los franceses. 
ese derecho, en un escenario - el revolucionario francés- que a priori, por los antecedentes y bases históricas con el que contaba, era proclive a facilitar, tras la caída del Antiguo Régimen, una configuración plena del concepto de ciudadano y la atribución a esa concepción de los derechos propios e ilimitados del sufragio. Se cuestiona igualmente si las dificultades que planteó en su momento el reconocimiento de ese derecho son extrapolables al momento presente.

A tal fin, se ha efectuado un estudio de las líneas de pensamiento predominantes en la época y que se consideraron como referencia en el proceso revolucionario, examinando directamente las mismas y poniéndolas en correlación con los textos constitucionales y las Declaraciones de Derechos que se otorgaron en el proceso revolucionario. Se trata, por tanto, de un examen directo de las fuentes documentales existentes que abarca también las críticas que merecieron ambos textos. Por razones sistemáticas se ha iniciado exponiendo, para facilitar su lectura, los términos en los que se redactaron las Constituciones de 1791 y 1793 para, a posteriori, ahondar en sus raíces ideológicas y, obviamente, en sus diferencias.

Hubiera sido deseable -mas por las limitaciones propias de extensión no ha sido posible- enlazar este análisis con el texto constitucional de 1795 que supuso un retorno no demasiado sutil a las posiciones políticas de 1791. Aspecto pendiente que trataremos de resolver en trabajos futuros.

\section{La regulación de la condición de elector y elegible del derecho de sufragio y de la propiedad en el texto de las Constituciones de 1791 y 1793}

La Declaración de Derechos del Hombre y del Ciudadano de 26 de agosto de 1789 contenía sucintas referencias a la participación política y la propiedad en los artículos 1 a 3 y $17^{4}$, las cuales se coordinaban con las igualmente escasas menciones que contenía el texto constitucional de 1791, pese a que algunas - principalmente

4 «Artículo 1. Los hombres nacen y permanecen libres e iguales en derechos (...) Artículo 2. La finalidad de cualquier asociación política es la protección de los derechos naturales e imprescriptibles del Hombre. (....) Artículo 3. El principio de toda Soberanía reside esencialmente en la Nación. (...) Artículo 17. Por ser la propiedad un derecho inviolable y sagrado, nadie puede ser privado de ella, salvo cuando la necesidad pública, legalmente comprobada, lo exija de modo evidente, y con la condición de que haya una justa y previa indemnización». 
las recogidas en el Título I- garantizaban el teórico ejercicio de los derechos políticos de todos los franceses ${ }^{5}$. Dichos derechos políticos incluían la elección de los representantes en la comuna (Título II, Artículo 9) y de la Asamblea Nacional (Título III, Artículo 3) aunque con las limitaciones fijadas para ser ciudadano activo ${ }^{6}$, elector (que implicaba ser propietario de una renta equivalente entre ciento cincuenta y doscientas jornadas de trabajo) y representante.

Se trataban de tres conceptos estrechamente ligados entre sí, puesto que la condición de ciudadano activo otorgaba la de elector que a su vez — con la periodicidad fijada en el propio texto- elegía a los representantes, cuya condición quedaba asimismo limitada por la de ciudadano activo del reino. La nominación de representantes exigía que cada dos años se elaborara una lista de ciudadanos activos (Título III, Capítulo I, Sección IV, Artículo 4), siendo dicha lista la que delimitaba la participación política a todos los efectos.

Por su parte, las referencias a la propiedad, más allá de la renta o contribución aportada, se limitaba una somera referencia en el sentido de garantizar su disfrute, salvo justa expropiación o al hacer referencia a la responsabilidad de los ministros por permitir la perturbación de la misma (Título III, Capítulo II, Sección IV, Artículo 5).

La Constitución de 24 de junio de 1793 -que incluía como Preámbulo la Declaración de Derechos del Hombre y del Ciudadano de la misma fecha - estableció una regulación planteada desde un prisma opuesto. Dicha regulación planteaba en el artículo 2 de la Declaración la igualdad y la propiedad como uno de los derechos naturales e imprescriptibles indicados en el artículo 1. Afirmaba a su vez que todos

5 «La Constitución garantiza, como derechos naturales y civiles: 1. que todos los ciudadanos son admisibles en los puestos y empleos (...) 3. que los mismos delitos serán penados con las mismas penas, sin distinción de persona. La Constitución garantiza así mismo (...) la libertad de todo hombre de hablar, escribir, imprimir y publicar sus pensamientos. (...) El Poder legislativo no podrá hacer leyes que mermen y dificulten el ejercicio de los derechos naturales; (...) pero como la libertad no consiste más que en poder hacer todo aquello que no dañe a los derechos de los demás, ni a la seguridad pública, la ley puede establecer penas contra los actos que, atacando bien la seguridad pública o los derechos de los demás, fueran perjudiciales para la sociedad. La Constitución garantiza la inviolabilidad de las propiedades, o la justa y previa indemnización de las que, por necesidad pública, legalmente verificada, se exija su sacrificio».

6 Título III, Capítulo Primero, Sección Segunda, 2 y 5: «Para ser ciudadano activo hace falta: Nacer o haberse hecho francés; tener la edad de veinticinco años cumplidos; estar domiciliado en la ciudad o cantón durante el tiempo determinado por la ley; pagar, en cualquier lugar del Reino, una contribución directa al menos igual al valor de tres jornadas de trabajo y acreditarlo con recibo.» 
los ciudadanos eran igualmente admisibles en cualquier empleo público (artículo 5), estando llamados a la creación de la ley y la designación de sus representantes (artículo 29).

El artículo 16 regulaba el derecho de propiedad como el derecho a disponer de los beneficios generados por sus bienes, ingresos y el producto del trabajo y la industria, no pudiendo prohibirse ningún tipo de actividad a los ciudadanos (artículo 17), ni privarles total o parcialmente de la propiedad de la que fueran titulares (artículo 19), salvo que la ley así lo estableciese, previa compensación justa y razonable. Los términos anteriormente indicados tenían su reflejo en el texto constitucional en el que se estipulaba que los ciudadanos franceses ${ }^{7}$ tenían derecho a elegir a sus diputados (artículo 8) a través de las Asambleas Primeras (artículo 11) y electorales (artículo 37), pudiendo ser elegible cualquier francés que fuera calificado como ciudadano (artículo 28).

\section{Ideas previas sobre ciudadanía, propiedad y sufragio}

La evolución de los tres conceptos no implicó necesariamente una ligazón entre ellos.

Locke $(1991,75)$ concebía la propiedad como una herencia propia que los hombres a través de Adán, habían recibido de Dios y que convertía al propio hombre en su concepto de ser humano creado a imagen y semejanza del Creador en el dueño de todas las cosas. Esa propiedad era compartida con los demás hombres, desechando que por ser Adán el primer hombre fuera de su exclusiva propiedad y tuviera la soberanía sobre las mismas (Locke 1991, 84). Esa duda permite que Locke se plantee cuál de los hijos de Adán o Noé —como primeros pobladores humanos - son los titulares de la soberanía paterna.

La primera solución, la transmisión de la soberanía a través de la tierra, fue criticada por el autor inglés puesto que, si la única fuente de poder procede de la tierra como forma de usurpación o derivación del poder paterno y el poder de la propiedad es supremo, el poder paternal es el que habrá de someterse a la propiedad y no podrá ejercitarse sin la licencia de los propietarios (Locke 1991, 120). Este

7 La condición de ciudadano francés se otorgaba a los nacidos y residentes en Francia, mayores de 21 años o extranjeros que residiesen en el país desde hacía un año, que trabajasen, estuvieran casados con un francés o hubieran adoptado un niño (artículo 4). 
mismo autor considera, por el contrario, que es posible entender que la autoridad real derive del dominio natural y el dominio privado de Adán, de la propiedad y la paternidad al mismo tiempo, siendo títulos esencialmente diferentes. Esa distinción entre dominio natural y dominio privado permite concluir a Locke $(1991,240)$ que los gobiernos están facultados para regular la propiedad, y esa propiedad exige que necesariamente se regule por medio del poder legislativo elegido, el cual establece las leyes a las que todos los hombres se encuentran plenamente sometidas, excluyéndose a aquellos que no las observen (Locke 1991, 272- 273).

Fija Locke, por tanto, dos líneas de atribución a su teoría del poder mediante el concepto propiedad y el concepto ley. Precisamente el concepto de un poder legislativo requiere de la formación de una comunidad civil a la que el hombre otorgue su consentimiento para formar parte de la misma. Desde ese instante renuncia de forma libre y voluntaria a su libertad natural y se sitúa dentro de los límites de la sociedad civil, sometiendo sus posesiones presentes y futuras a la comunidad en la que se incardina, siempre y cuando tales posesiones no formasen parte previamente de ningún otro gobierno.

Locke (1991, 290-296) estima que la creación de un gobierno civil o poder legislativo incita al hombre a unirse en repúblicas y someterse a un gobierno con el fin último de preservar sus propiedades; defensa ésta ciertamente complicada en el propio estado de la naturaleza. La existencia de un poder superior que engloba a una de las ramas de transmisión de poder originarias - la propiedad - exige obediencia a ese único poder, a cambio de renunciar a la igualdad, la libertad y el poder ejecutivo del que disfrutaba y que es entregado al poder legislativo para que lo administre, por cuanto ese poder es depositario de la voluntad del conjunto de la sociedad.

El poder legislativo no puede privar ni imponer exacciones contra la voluntad y consentimiento del pueblo, ni puede fijar leyes arbitrarias o irracionales, ni tampoco ceder el poder a terceros que no han sido previamente designados (Locke 1991, 305-317). La apropiación del poder legislativo de la propiedad de los hombres que le han otorgado voluntariamente su consentimiento - precisamente para que defienda su propiedad - le sitúa en guerra con el pueblo, facultando a éste para que desobedezca y constituya un nuevo poder legislativo, retirándole su confianza e incluso, empleando la fuerza en su defensa (Locke 1991, 365-366).

La elección de los representantes, según Locke (1991, 320-321), debía acometerse con criterios de proporcionalidad, atendiendo a un sistema justo y equitativo, sin perjuicio de que pueda verse modificado 
en el transcurso del tiempo. Huelga precisar que Locke, partiendo de los antecedentes expuestos en el common law, refuerza el poder del concepto de propiedad, ciertamente arraigado en el derecho inglés, reforzando su peso en la atribución de las facultades políticas. Su pensamiento fue parcialmente adoptado por los posteriores pensadores franceses, aunque eludiendo la trascendencia del concepto de la propiedad.

Mably $(1865,8-11)$ reconocía al hombre la condición de ciudadano por su nacimiento, pese a que ese ciudadano no era necesariamente propietario. Es un sujeto que busca su felicidad conforme a la determinación de una serie de reglas fijadas con sus conciudadanos, aceptándose sacrificios por ambas partes en base a las leyes elaboradas de forma conjunta al reunirse en sociedad.

A pesar de que Mably $(1865,86)$ reconocía que la propiedad particular era el bien más preciado para el ciudadano y debía ser garantizada por las leyes civiles, no ocultaba el hecho de que la propiedad era causa y conflicto entre los hombres y resultaba necesario establecer la forma de distribución de la propiedad entre los nuevos ciudadanos para aliviar las desigualdades existentes. Proponía la creación de almacenes públicos donde se depositaran los frutos del trabajo que se asignarían en función de las necesidades de cada particular y la fijación de impuestos sobre los bienes de los particulares para satisfacer las necesidades del Estado, obviando la aquiescencia a los mismos por parte de los afectados.

La representatividad se alcanzaría a través de una elección por provincias, entendiendo Mably $(1865,31)$ que, en todo caso, aun de una forma imperfecta, el hombre debía participar en el gobierno y obedecer las leyes en cuya elaboración había participado. Podría además emplear sus facultades personales para alcanzar el triunfo de una revolución útil a su patria. Caso de que fuera necesario luchar contra los tiranos, dicha acción no sería criticada, por estimarse propia de un hombre virtuoso (Mably 1865, 53).

Se inicia así con Mably la tendencia a reconocer al hombre, por su mera condición, la capacidad de ostentar derechos políticos. Esto no impidió, sin embargo, que Montesquieu (1987, 11-13) atribuyera al hombre la designación de los ministros a través del mecanismo por delegación, afirmando a su vez que la mayoría de los ciudadanos tenían capacidad para elegir y no para ser elegidos. Esa disparidad fijaba una teoría de democracia asimétrica que otorgaba plena capacidad para los electores pero más restringida para los elegibles.

Si bien aceptaba la democracia como el único sistema en el que existía de verdad el amor a la patria y las leyes y permitía que todos los 
ciudadanos tomasen parte en el gobierno, no extendía esa participación a la capacidad de representación sino exclusivamente a la facultad de elección. Esa discrepancia obedecía a que, aunque aceptaba que la participación del pueblo en el sufragio resultaba indispensable para no repetir los errores de la Antigua Roma que impidió la libertad, exigía que el sufragio fuera además público, especificándose las normas en virtud de las cuáles se otorgaban los votos (Montesquieu 1987, 119). No era preciso vincular los derechos políticos a la propiedad, la cual únicamente debía ser objeto de protección por los tribunales (Montesquieu 1987, 53). Asimismo, podían establecerse tributos sin precisar del consentimiento de los ciudadanos (Montesquieu 1987, 150).

No obstante, la concepción más amplia de ciudadano se debe a Rousseau, que la ligó al concepto de soberanía dimanante de la voluntad popular o colectiva. La ciudadanía era para Rousseau la forma de participación colectiva que tenía por objeto proteger los intereses del sujeto, quien cede los mismos al conjunto o ente del que participa. Por tanto, el concepto de ciudadano deriva del derecho natural del hombre en sociedad y nace de su asociación voluntaria con otros hombres, teniendo un carácter inalienable (Gauthier 1992, 19-21). Rousseau avanzó en el concepto que primigeniamente había sentado Locke sobre la asociación política voluntaria entre los distintos hombres, que otorgaban los derechos políticos a su soberano.

Asimismo, entronca con la concepción de ciudadano anticipada igualmente por Mably (1865) — superando a Montesquieu - que disponía que el ciudadano era aquel que proponía una forma política más sabia derivada de la propia consciencia y voluntad de los sujetos, avanzando hasta un punto más complejo ya que entrelaza la idea de ciudadano y sufragio, convirtiendo el derecho de sufragio en un derecho inalienable para el pueblo. No se le podía despojar del mismo aunque quisiera, ya que solo la voluntad general obligaba a los particulares, y una voluntad particular solo es conforme a la general cuando ha sido sometida al sufragio libre del pueblo (Rousseau 1988, 38).

Precisaba Rousseau (1988, 95-100), sin embargo, que solo una ley, la del pacto social, reclamaba unanimidad, puesto que la asociación civil es el acto más voluntario de todos y se convierte en voluntad constante pudiendo obligarle, a pesar de no estar de acuerdo. Al dar su voto, el ciudadano emite su opinión, y con ella ha de estar conforme, sin perjuicio de que se celebrasen asambleas periódicas que permitiesen el sostenimiento del pacto social.

Rousseau $(1988,16)$ definía igualmente el concepto de ciudadano como el pueblo o asociados, como partícipes de la voluntad soberana y 
súbditos por estar sometidos las leyes del estado, pudiendo tener una voluntad contraria o desigual a la voluntad general. Los ciudadanos deben ser iguales ya que se obligan bajo las mismas condiciones y gozan de los mismos derechos (Rousseau 1988, 29), desdeñando la propiedad como parte del haz de derechos del sujeto e incorporándolo al pleno disfrute de sus facultades políticas.

\section{La concepción opuesta de ambos textos}

\subsection{La regulación en el texto constitucional de 1791 y la perspectiva de Locke y Montesquieu}

La determinación y el alcance de los derechos objeto de análisis vino establecida por la situación política, por las mayorías de la Asamblea Nacional existentes en cada momento y por la ley que se convirtió en el común denominador de la regulación promulgada. El derecho de propiedad estaba reconocido formalmente, pero su alcance real estaba supeditado a una suerte de función pública que difería de los derechos reconocidos en otras partes de Europa (p. ej. Inglaterra), donde incluso se le otorgaba determinadas prerrogativas personales, a pesar de que se institucionalizó como parte de los derechos subjetivos del hombre y derivado de su propia naturaleza (Cordero y Aldunate 2008, 379). Sin embargo, esa regulación convirtió a la propiedad en base de la libertad política (Álvarez Alonso 1999, 196-197).

No obstante, el poder económico se encontraba huérfano de referencias en la Declaración de Derechos de 1789 (Lefebvre 1968, 148). A la supresión del derecho de diezmo que conllevaron los Decretos de Agosto le siguieron los derechos de servidumbre que gravaban la tierra. Esto supuso que la burguesía y campesinos acomodados exigieran que se garantizara un concepto, impropiamente francés y legítimamente anglosajón, que era la propiedad plena. Se requería que la misma fuera individual, total y sin más limitaciones que lo ajeno y las necesidades estrictamente tasadas del bien público.

Esta opción fue rechazada por la Asamblea constituyente al ir en contra de la idea de que la pérdida de propiedad de nobleza y clero debía aprovechar al conjunto del país y, en concreto, a la comunidad campesina en su totalidad. No obstante, y debido a la dificultad que los campesinos tenían para el acceso al crédito, no les era posible convertirse en propietarios, simplificando la sustitución entre los antiguos propietarios y los nuevos propietarios legítimamente constituidos por la Asamblea Constituyente. 
Semejante problema se planteaba con la libertad de producción y trabajo. La primera pretendía la supresión de corporaciones de gremios y monopolios reales. Al inicial Decreto de 11 de agosto de 1789 (Lefebvre 1968, 149-150) que regulaba la cuestión, le siguió la Ley Allarde, que en marzo de 1791 suprimió corporaciones, cofradías y señoríos, permitiendo la libre competencia, así como la libre fijación de precios, producción y salarios. Tal cambio conllevó a su vez que se liberase el mercado de trabajo, prohibiéndose las cuadrillas o coaliciones de trabajadores, pues en un entorno productivo libre, cada ciudadano era libre de disponer si decidía acudir a prestar servicios en un lugar u otro. La libertad de trabajo vino acompañada de una libertad de comercio mediante la supresión de gabelas, la liberalización del precio del grano, así como las concesiones, ayudas y demás impuestos al consumo que fueron progresivamente suprimidos entre 29 de agosto de 1789 y 2 de marzo de 1791.

Al disminuir la carga impositiva, el mercado negro afloró y el grano existente comenzó a circular con mayor rapidez en comparación con lo vivido en los últimos años. Paralelamente a lo anterior, la Asamblea Constituyente inició la que era una de las reformas más esperadas: la fiscal. Se suprimieron con carácter general los impuestos indirectos y se crearon tres grandes impuestos directos (Lefebvre 1968, 176180): i) contribución territorial que gravaba la tierra; ii) la contribución mobiliaria que gravaba los alquileres de vivienda; iii) la patente que gravaba los ingresos del comercio y la industria. La problemática se generó cuando se estableció que los municipios serían los encargados de su recaudación. Estas entidades carecían de conocimientos y medios que se suplieron acudiendo a los gravámenes y datos que poseían de los impuestos reales, en su mayoría desactualizados o erróneos.

A resultas de ello, el pueblo llano apenas vio mejorada su situación mientras que la burguesía, que realmente era la que tenía la riqueza, se vio ciertamente beneficiada. Pese a que el nuevo sistema contaba con evidentes ventajas, principalmente su sencillez y carácter eminentemente práctico, su implantación precipitada y la falta de medios obligaron a la Asamblea Constituyente a decretar la amortización de los bienes del clero y la emisión de asignados (Lefebvre 1968, 188-189). Ambas medidas no contribuyeron a salvar la situación económica.

La primera, porque aparte de que la venta fue lenta y plagada de dificultades, facilitó la adquisición por medio de aquellos que contaban con medios económicos para ello, principalmente campesinos acomodados y burguesía. El campesinado en general y el pueblo llano carecía de medios para adquirir tierras y de crédito para financiarse. Por 
tanto, la esperada redistribución de la riqueza no se produjo. El proceso de emisión de asignados incluía una deuda garantizada con los bienes eclesiásticos que exigía que se produjera su venta y, al no producirse ésta, se convirtió en el papel moneda oficial. La necesidad de ese papel moneda obligó — por la imposibilidad de enajenar dichos bienes- a imprimir más papel, con lo que su valor apenas un año más tarde era un 25\% menor. Este efecto se dejó sentir en los obreros y pueblo llano, que vieron disminuir su nivel de vida rápidamente.

La situación existente favoreció la expansión de las ideas de Locke y su adopción en la Constitución de 1791. El reconocimiento del trabajo y de la propiedad, su transformación en propiedad y la transmisión de esa propiedad, con la limitación única del poder legislativo, son conceptos claramente lockianos, calando de una forma más profunda de lo que una mera lectura del texto desprende. Así, las primeras decisiones que tuvieron por objeto liberalizar el mercado de trabajo como una fórmula de ruptura con los gremios y el sistema de producción de origen medieval, da paso a un proceso liberalizado en el que el hombre puede decidir cuándo y para quién presta servicios.

Esa libertad redunda en la necesidad de que pueda hacer suyos los frutos de su trabajo y, en base a esos frutos, adquirir la expresión máxima de la libertad económica que es la propiedad, la cual además solo puede ser delimitada por el poder legislativo. Lo anterior permite que el derecho de propiedad — como sucedía en la Corona inglesaotorgase el acceso al estatus o posición de ciudadano con plenitud de derechos, traduciéndose en la capacidad de ser elector y elegible, ya que la imposición de tributos requiere el asentimiento y aquiescencia del sujeto. Ciudadano, propietario y elector.

La futura Constitución limitó el derecho de sufragio a los propietarios, creando una sociedad activa (tenedora de la riqueza) ${ }^{8}$ y otra pasiva (que carecía de ella) y que, por tanto, se distinguía en función de su posesión o no (Robespierre 1866, 195) ${ }^{9}$. Era una sociedad propiamente más inglesa que francesa, ligada al pensamiento de Locke. Tal vínculo excluía una idea igualitaria de los derechos políticos, para defender la propiedad como un elemento clave del sistema.

Como consecuencia lógica y directa, se produjo que pese a la sustracción al clero y a la propia Corona de la propiedad existente,

8 En palabras de Marat (1869, 67-68): «hombres opulentos, sin educación o influidos por una educación viciosa».

9 Robespierre tildó esa prohibición de antisocial y anticonstitucional porque la limitación y exigencia de la propiedad implicaba desposeer a la mayoría de la Nación de sus derechos políticos. 
el pueblo llano seguía excluido de la actividad política, ya que dichas propiedades habían sido adquiridas por clases acomodadas que habían podido abonar su precio. Esta decisión provocó una enérgica protesta por parte de Robespierre y de sus seguidores ${ }^{10}$. Protesta que tuvo su eco en sus órganos de expresión ${ }^{11}$ que dirigieron una súplica a la Asamblea Nacional (Marat 1869, 111-114).

El acceso a determinados derechos políticos suponía la creación de una especie de homo economicus (Lucas 1991, 69-72) que absorbe a su vez al homo politicus creado por Locke, aglutinando no solo los principios lockianos de libertad de propiedad sino también del mercantilismo de «laissez-faire, laissez-passer». Se apropiaron igualmente de la perspectiva política (Robespierre 1866, 195), reclamando para sí que solo los contribuyentes máximos al Estado pudieran decidir su futuro y en conjunto el de todos los franceses, lo que fue considerado por Marat $(1869,127)$ como una afrenta al derecho del pueblo a ser libre y feliz.

La propiedad se tornó entonces en un concepto controvertido y contrario a la igualdad. Barnave $(1988,61)$ la significaba como el punto de origen de la aristocracia, ya que su obtención había sido mediante regalo o conquista, contraponiéndola a la riqueza industrial lograda a través del trabajo. Identificaba la propiedad inmobiliaria con el federalismo y la propiedad mobiliaria, lograda mediante el trabajo, con la democracia y la unidad, pese a que esta concepción obviaba que Locke atribuía la propiedad al trabajo, salvo aquélla que se había otorgado por la acción divina. En todo caso, el modelo propuesto por Locke contaba con adeptos en la propia Francia, siendo el primero de ellos Montesquieu, que aceptaba expresamente la limitación de parte de los ciudadanos para ostentar la condición de elegible. No vinculaba esa limitación a la tenencia de bienes o a la propiedad de los mismos,

10 Marat (1869: 102) lo expresó así: «la representación, convertida en proporcional según la contribución directa, pondrá el imperio en manos de los ricos, y la suerte de los pobres, siempre sumisos, siempre subyugados y siempre oprimidos, no podrá jamás mejorarse por medios pacíficos. Ésta es, sin duda, una prueba grave de la influencia de las riquezas sobre las leyes. En cuanto a lo demás, las leyes sólo tienen poder mientras los pueblos quieran someterse, y si han roto el yugo de la nobleza, romperán también el de la opulencia» (Traducción del autor).

11 Desmoulins $(1790,109)$ no fue menos vehemente: "Acaba de constituir a Francia en Gobierno aristocrático, y es la victoria mayor que los malos ciudadanos hayan logrado en la Asamblea Nacional. (...) Los ciudadanos activos son aquellos que han tomado la Bastilla, son aquellos que han arado los campos, mientras que los ociosos del clero y de la Corte, a pesar de lo inmenso de sus dominios, no son sino plantas parecidas a ese árbol de vuestro Evangelio, que no da fruto alguno y que hay que echar al fuego» (Traducción del autor). 
pero suponía igualmente un menoscabo de la capacidad política del ciudadano francés.

Todo ello supuso que se retornase al origen de la propiedad o la limitación de la misma en términos medievales, al ser en el Medievo la única forma de riqueza existente y que fue acaparada por la nobleza. Las posteriores reformas de los siglos XVI y XVII que limitaron el campo de la nobleza en el comercio y la industria, estimularon la entrega de la propiedad a la nobleza (Tocqueville 1994, 13), y convirtieron a la propiedad en el objetivo último de las demás clases sociales. Es el nacimiento de la sociedad fisiocrática que dividió a Francia en dos clases: propietarios y no propietarios, y que fue la precursora para la reorganización administrativa del Estado (García de Enterría 1986, 83-84).

El sujeto propietario se convierte así en el único que cuenta con los derechos jurídicos necesarios para decidir y, en su caso, mejorar su posición gracias a la propiedad que posee. Esa propiedad le otorga amplias facultades para ello, ya que no puede ser desposeído más que en los casos previstos en la ley, y solo está obligado a pagar los impuestos fijados por los representantes de la Nación, siempre y cuando fueran necesarios para el mantenimiento de las necesidades públicas (Sánchez Viamonte 1956, 171). Aunque Montesquieu (1987, 149-152) consideró que un mayor grado de libertad implicaba la posibilidad de fijar impuestos más elevados.

Críticas furibundas aparte, no era precisamente una concepción muy acorde con el espíritu en el que teóricamente algunos revolucionarios habían tratado de inspirar la norma, que no era otro que la «voluntad» roussoniana plena, absoluta y generalizada, la cual presuponía que no era solo fuente de las leyes sino además raíz del patriotismo de los ciudadanos (Rousseau 1923, 57) aunque Rousseau no dejaba de reconocer que la propiedad era un mal necesario (Babeuf 1988, 207-212).

Tal caracterización conllevaba la construcción de un modelo político en el que todos los ciudadanos debían ser capaces de elegir y decidir su futuro (Robespierre 1866, 276), no pudiendo limitarse a unos pocos esa decisión ya que, a ojos de Rousseau, suponía retornar a los postulados del soberano absoluto de Hobbes. Precisamente esa imposibilidad de que la voluntad del pueblo fuera absoluta, es uno de los primeros obstáculos con los que se encuentra la Revolución al tratar de redactar la Constitución de 1791 (Barnave 1988, 99). La pretensión de las facciones más extremistas, lideradas principalmente por el Club de los Bretones así como por los hebértistas, condujo a los sectores más moderados a evitar una ruptura total con el sistema 
anterior, buscando en primer lugar aunar todos los apoyos posibles y, en segundo lugar, facilitar - aunque pueda parecer contradictoriola implantación del movimiento revolucionario, si bien alejado de sus postulados más primigenios y respetando el reconocimiento de los derechos económicos logrados en el marco de la Revolución y que eran, a su vez, ruptura con el Antiguo Régimen. Derechos que obligaban a facilitar la participación política de sus titulares por encima del conjunto de la población.

Las posteriores experiencias revolucionarias - principalmente el período conocido como Terror y en concreto en el texto constitucional de 1793 al que nos referiremos a continuación- en la que se sacralizaron los conceptos roussonianos, conllevaron su abandono progresivo ante - ahora sí - la evidencia práctica de su controvertida aplicación (Zarka $2006,63)$. La propiedad, al igual que otros muchos conceptos de la Francia revolucionaria, se asentó en el sistema como medio de delimitar los derechos políticos del sujeto. Un asentamiento parcial y temporal que sería revocado con el texto de la Constitución de 1793, pero sobre el que se retornaría en 1795. En todo caso, no llegó a ser un derecho absoluto al estilo lockiano, ya que podía ser ponderable en función de lo que la ley fijase, pero de partida, incluía una vertiente política censitaria que restringía la participación política en el sistema.

Precisamente esa concepción plenamente individualista y absoluta no se vería lograda hasta la redacción del Código Civil napoleónico (Código Civil 1829, 77), cuyo artículo 544 («la propiedad es el derecho de usar y disponer de las cosas de la manera más absoluta»), reconoció de forma plena el derecho de propiedad. Plenitud que le había sido negada por la Revolución (Cordero y Aldunate 2008, 381-385) y que con la redacción del citado precepto, permite afirmar que Locke vio finalmente alcanzadas sus expectativas más elementales.

\subsection{El texto constitucional de 1793. El triunfo de Mably y Rousseau}

La Constitución de 1793, imbuida de los principios roussonianos y promulgada bajo el apogeo de la Montaña, presentó un carácter marcadamente opuesto al del texto constitucional anterior. Proclamaba una igualdad plena y una, a priori, libertad absoluta en materia de propiedad vinculada a un reconocimiento de los derechos políticos para todos los ciudadanos (Robespierre 1866, 269).

Sin embargo, la realidad es que - aparte de la suspensión en su entrada en vigor derivada de la guerra que mantenía Francia con las demás naciones europeas - el derecho de propiedad se vio claramente 
minorado por la política económica marcada por el Comité de Salud Pública (Lefebvre 1968, 355-356) y que el derecho de sufragio estuvo bajo continua supervisión del partido jacobino y su brazo armado, los sans-culottes. Se avanzaba hacía una política de igualdad plena, en la que la propiedad se restringía al máximo como un fin, por entender que la misma debía asegurar la subsistencia del sujeto en términos estrictos, obligando a que los ciudadanos más acaudalados sufragasen - vía impositiva - la subsistencia de los que carecían de medios de vida (Robespierre 1840, 351-360).

Era la sublimación de la persona sobre los bienes y la supeditación de la principal causa de conflicto o, conforme al ideario de Mably, el triunfo del reconocimiento del derecho de nacimiento que implicaba la condición de ciudadano sobre la principal causa de desigualdad que era la propiedad. La política económica se vio claramente restringida tras la implantación de la política del máximum (Lefebvre 1968, 367) y una subida generalizada de impuestos que no permitió mejorar la situación existente, produciéndose un desabastecimiento generalizado a finales de 1793. Se obviaron políticas como las propuestas por Nicolás de Caritat, Marqués de Condorcet (1847, 1-12), que apostaba por un comercio libre en el que el mercado, con ayuda de una cierta supervisión y control de precio, se autorregulase. Se subrayó que el producto de la tierra pertenecía a quien lo cultivaba o pagaba por él, siendo la libre circulación de mercaderías una consecuencia necesaria y directa del derecho de propiedad y de la igualdad de los hombres.

La creación de la Comisión de subsistencia en octubre de 1793 comenzó a practicar requisas de forma masiva bajo el control del Comité de Salud Pública (Robespierre 1840, 31-42), apoyándose en la unidad administrativa del distrito, recientemente creada. Sin embargo, y pese a la autonomía que se otorgó al distrito y a los municipios que realizaron una labor eficiente en materia de requisas, no se solventó la problemática del nivel salarial experimentándose un descenso del nivel de vida (Bouloiseau 1962, 93-95), aunque se colectivizaron infraestructuras y se centralizó el reparto de alimentos.

Estas políticas seguían sin satisfacer a los sans-culottes, quienes consideraban que se les pagaba con los despojos del resto de la sociedad a pesar de que el 2 de frimario (22 de noviembre de 1793) se decretó la venta de bienes nacionalizados y se promulgaron otras medidas sociales como la creación de escuelas que pretendían evidenciar la existencia de un trasfondo social en la política económica implantada.

La propiedad era un reflejo del pensamiento del partido jacobino que la consideraba como un derecho que podía ser constreñido si 
el bien común así lo requería (Martin 1963, 88-89) y como máxima de expresión de la igualdad que el nuevo régimen establecía (Soboul $1979 b, 65)^{12}$. Y ese bien común (Robespierre 1866, 203) permitía que los desposeídos tuvieran derecho a recibir los bienes de los ricos y los antiguos propietarios que pasaban a ser sospechosos y, por tanto, enemigos del Estado.

Aunque la propiedad era inalcanzable para parte de los miembros del sector jacobino, y esa carencia había limitado en el pasado el acceso a sus derechos políticos, se trató de potenciar ese acceso, considerando propiedad -en términos de sufragio- la mera posesión (que ya había permitido mantener algunos de los derechos de la nobleza en el texto de 1791) (Álvarez Alonso 1999, 200-201), relativizando, por tanto, de forma absoluta el concepto de la misma en aras de facilitar la participación política.

No era más que una forma de hacer partícipe al conjunto de la población del concepto de «voluntad general» mediante el otorgamiento de su propia conformidad a los representantes políticos, y adhiriéndose al compromiso que en el marco legislativo estos alcanzasen. Se facilitaba asimismo la supresión de desigualdades al permitir reducir las diferencias entre propietarios y no propietarios desde una perspectiva de participación política, y se justificaba además la colectivización de los medios productivos y la obligación de compartir los bienes agrícolas.

Los periódicos, como el Ami du peuple, clamaban por declarar que dichos bienes eran propiedad de la República, sin perjuicio de que se abonase una compensación al agricultor por el trabajo realizado. El producto de la tierra debía corresponder al pueblo y el resto de la actividad económica no podía superar el tener un pequeño negocio o una tienda (Soboul 1979b, 67 y 70). Se apostaba por una clara redistribución forzosa de la riqueza (Lefebvre 1968, 410-411) como medio de equilibrio y argumento básico de la igualdad, destinado a lograr esa igualdad en la participación de los asuntos de Estado. Esa redistribución alcanzó igualmente a la circulación del dinero en efectivo, el cual experimentaba una clara inflación debido a la pérdida de valor «asignado», cuyo contravalor en dinero decaía paulatinamente de forma irreversible. El 7 de frimario un Decreto del Consejo vetó la circulación de dinero en efectivo hasta que se alcanzase la paz, reduciendo el peso e importancia de los ciudadanos más acaudalados.

Más allá de la trascendencia ideológica de esta decisión, tras ella se ocultaba una decisión práctica derivada de la pérdida de poder

12 La desaparición de la riqueza y la pobreza a la que nos hemos referido anteriormente. 
adquisitivo de la población. El cierre de la Bolsa el 27 de junio de 1793 fue una medida igualmente estética reclamada por la base social de los sans-culottes, que evidenciaba la hostilidad hacia los aspectos financieros y económicos (Soboul 1979b, 76). Esta persecución alcanzó igualmente a las compañías financieras y a todas en general mediante sendos Decretos del 24 de agosto de 1793 y el 26 germinal.

Esto, sin embargo, planteó un problema desde el punto de vista de la defensa nacional, ya que no existían compañías capaces de asumir los encargos realizados y necesarios para nutrir a las tropas que estaban combatiendo a los enemigos de la República (Lefebvre 1968, 402). Se planteó la posibilidad de que dicho trabajo fuera encomendado a las mujeres necesitadas de los sans-culottes y que se retirasen los encargos a las empresas que venían ejecutándolos habitualmente. Una nueva muestra de hostilidad al capital como muestra de monopolio comercial (Soboul 1979b, 80) que se convertía —-según el criterio de los sansculottes - en una nueva aristocracia comercial, lo que en definitiva era un enemigo del pueblo y contraria a la formación de la voluntad general.

La lucha contra la propiedad conoció igualmente un capítulo aparte en el marco de la política impositiva (Lefebvre 1968, 401). Se pretendía que los ciudadanos adinerados pagasen más impuestos para compensar los beneficios que percibían del Estado, y se entendía como un medio de colaboración con la salud del Estado, a falta de un mayor talento (Danton 1910, 411-415). Esta posición no resultaba exclusiva del partido jacobino sino también de la Gironda (Nicolás de Caritat, Marqués de Condorcet 1981, 17-18), aunque se trató de que - a diferencia de otras posturas que justificaban la imposición de un impuesto progresivo que sería exigible a los ciudadanos más pudientes para que estos colaborasen con la economía- esa acción recaudatoria no tuviera como efecto secundario la ocultación de la riqueza, destruyendo la capacidad productiva de la nación.

Se generalizaron las llamadas colectas voluntarias que tenían por objeto sostener el esfuerzo de la guerra que se venía manteniendo, pese a que la Declaración de Derechos de 24 de junio de 1793 incluía dentro de los derechos naturales e imprescriptibles a la propiedad, ligándola al derecho de existencia que, a su vez, contaba con el derecho de garantía social presente en el artículo 23 de la propia Declaración (Robisco 1998, 94). Esa garantía social se convirtió en un instrumento esencial para establecer la reivindicación de una mayor justicia en materia económica. Este medio facilitaba además el control de los términos de la asociación proclamada por Rousseau, encaminada a asegurar la pequeña propiedad que sostenía la subsistencia de cada 
uno de los hombres (Robisco 1998, 97), impidiendo y cercenando, además, el surgimiento de opiniones discrepantes en la llamada voluntad colectiva.

Esta práctica se regularizó mediante la Ley de 13 de frimario del año III en la que se estableció la obligación de rendición de cuentas de las autoridades que hubieran percibido impuestos revolucionarios o que hubieran forzado colectas voluntarias o forzosas. La presión sobre los ciudadanos más adinerados para contribuir al esfuerzo bélico se prolongó durante todo 1793, aunque no sería hasta la Ley de 14 de frimario cuando únicamente se autorizan las colectas voluntarias sin que pudieran imponerse de manera forzosa lo que no había sido práctica inusual (Soboul 1979b, 86). De todas formas, no hay que engañarse. Las colectas voluntarias estaban teñidas por la preocupación de los ciudadanos con mayor poder adquisitivo de que se sospechase de su falta de civismo.

Incluso algunas secciones de París promovieron el gravamen de un impuesto de hasta el décimo del valor de los bienes muebles e inmuebles, salvo en concretas excepciones, llegando incluso algunas secciones a aplicar un impuesto del 20\%. Esta carga no afectó especialmente a los ricos, pero sí a los pequeños propietarios y artesanos, los cuales eran en su mayoría sans-culottes (Soboul 1979b, 89).

Los hechos permiten comprender la regulación del derecho de sufragio y la condición de ciudadano que se recogió en la Constitución. Se escindió el binomio ciudadanía y propiedad, pese al reconocimiento que se efectuó del derecho de propiedad tanto en la Declaración de Derechos como en el texto constitucional de 1793. Se vació la propiedad de significado propio para justificar su escisión del concepto de ciudadanía y, por tanto, del sufragio. La «maldad» intrínseca de la propiedad como causa de enfrentamiento entre hombres, ricos y pobres, desaparecía, y la propiedad o carencia de ella fue sustituida por un difuminado concepto de posesión que vigorizó la entrega de los derechos políticos al conjunto de la sociedad.

Era la adopción del pensamiento más rousseaniano, que fue convertido en estandarte por la facción jacobina predominante en la Asamblea y que supeditaba la propiedad y cualquier otra circunstancia a la voluntad colectiva emanada del conjunto de la población, estableciendo un férreo control sobre la misma (García de Enterría 1986, 123-124). La condición del hombre por su propio nacimiento es el nexo de unión entre Rousseau y Mably. La propiedad desaparece en ambos autores del haz de derechos básicos y esenciales del hombre, debiendo ceder ante el propio sujeto y la comunidad que éste cree con los demás ciudadanos. Es el Estado y el conjunto de la población la que 
debe proveer los mínimos de subsistencia, porque son derechos del hombre. La propiedad no es un elemento esencial del sujeto ni debe conferirle derechos políticos.

No resulta difícil ver esa correlación entre el texto Constitucional de 1793, que no delimita ni excluye del derecho de voto por razón de la propiedad, y las medidas adoptadas durante el Terror en materia de requisas, propiedad e impuestos. Esa misma perspectiva se advierte en Rousseau, que asumía el derecho natural del hombre a ser ciudadano no pudiendo enajenarse dicha condición. Es indiferente que posea, sea propietario o no lo sea. Tiene un derecho natural a su condición y no puede cederlo.

Esa condición de ciudadano es la que permite que avance hasta un estadio más evolucionado en el que el hombre forma parte de un colectivo en el que entrega su voluntad y que exige su adhesión formal. Es, por tanto, una fórmula que requiere expresamente que el hombre manifieste formalmente esa adhesión para que tenga efectos, formalizándose dicha adhesión a través del ejercicio del sufragio y que, en definitiva, fue la que trató de establecer de forma imperativa la Montaña en el texto constitucional de 1793.

\section{Conclusiones}

El carácter asimétrico del derecho de propiedad en las Constituciones de 1791 y 1793 y su traslación al derecho de sufragio radica en la conceptuación que del sujeto se tenía en ambos textos. La redacción de 1791, inspirada en los postulados de Locke y Montesquieu (quienes trababan la condición de ciudadano a la condición de propietario), influyó en la limitación de la capacidad para ser elector. Se trataba de un reflejo de la sociedad francesa de la época, la cual —pese al proceso revolucionario- no pudo evolucionar al ritmo deseado por las posiciones más extremas de la Revolución, y que otorgó a la propiedad el reflejo supremo de la condición y esfuerzo del hombre, convirtiéndolo en un criterio esencial para la atribución del poder político y para ser considerado elector y elegible.

La posterior caída de la monarquía y de la Gironda y la aparición de un nuevo escenario político permitió la implantación, apenas dos años más tarde, de un nuevo texto constitucional que ofrecía un acceso ilimitado al derecho de participación política, en el que el derecho al voto nacía de la propia condición y reconocimiento del hombre como ciudadano y miembro de pleno derecho en el marco del sistema. Era una modificación esencial, ya que la condición de sujeto — vinculado 
por un contrato social con la comunidad- se presuponía por la mera existencia, sin necesidad de acreditar la pertenencia a un grupo concreto dentro de la Nación o la titularidad de bienes o derechos.

La supresión de la importancia de la propiedad y el dinero en el marco de la sociedad obligó a despojar al hombre de cualquier atributo externo, limitando su capacidad a su propia condición de integrante del conjunto de la sociedad, facilitando así la uniformidad en el trato y en la supeditación de sus derechos. Se trataba de una idea simple: una Nación, muchos hombres, muchos votos, pero una sola voluntad general.

Huelga decir que la perspectiva más cercana a la sociedad contemporánea es la recogida en el texto de 1793. Una igualdad plena y un acceso al derecho de voto sin cortapisa alguna. Sin embargo, tampoco podemos hablar de una mímesis absoluta ya que los postulados jacobinos no casan adecuadamente con las poliédricas libertades individuales que el sujeto tiene a día de hoy y que eran englobadas por el partido de la Montaña en la voluntad general, supeditándola a la misma.

Esa falta de trasposición de los derechos autónomos del sujeto lastra la incorporación de la concepción del sufragio jacobino como elemento igualitario de la sociedad de forma plena a nuestro tiempo. Siendo discutible qué hubiera ocurrido si el texto constitucional de 1793 no hubiera quedado en suspenso, lo cierto es que la supeditación del sujeto al contrato social y la cesión de derechos que realiza al colectivo difuminan la importancia real que el individuo pudiera tener en la formación del ideario político, ya que los sujetos roussonianos -y los ideados por Mably - asumen los sacrificios necesarios en la formación de esa voluntad, hasta un punto que la corta experiencia jacobina demostró extremo.

Por otro lado, el texto de 1791, alejado de nuestros estándares políticos actuales, no deja de presentar una sorprendente verosimilitud en los procesos electorales actuales, que insistentemente obligan por medio de la representación a entregar la cuota necesaria de legitimidad a los representantes, acatando en su caso, las decisiones que estos adopten. Esquema político que pese a dotarse en la actualidad de modelos participativos, sigue resultando, en muchas ocasiones, estanco.

Así, observamos que, sin perjuicio de que ambas líneas fueran paralelas sin llegar a entrecruzarse, la problemática que planteaban en su momento continua vigente: i) por un lado, el problema lockiano de la participación política electiva y la vinculación del sujeto de las decisiones que se adopten, aunque no esté de acuerdo con el 
contenido o forma de las mismas, irresoluto en nuestros sistemas políticos actuales; ii) la necesidad de expandir el concepto de sufragio de manera que recoja los demás derechos individuales del sujeto, siendo ese derecho de sufragio la forma de proyectar los demás elementos subjetivos del individuo, evitando que queden minimizados en la mera participación en el proceso electoral y supeditados a la decisión de la colectividad general.

Ambas cuestiones no cuentan con una solución fácil, sin embargo, en relación a la primera, podemos buscar una resolución en el mismo autor que sugirió su problemática. Locke consideraba que la defensa de la propiedad exigía que el hombre se uniera a la comunidad y entregase a ésta su libertad natural, autorizando al poder legislativo para que defendiera su propiedad. Pero, sin embargo y al mismo tiempo, ese sistema permitía al pueblo sublevarse cuando el poder legislativo no cumpliese con la función básica de defensa de la propiedad.

No siendo necesario alcanzar el punto de la sublevación civil por no compartir las decisiones del poder legislativo, sí es cierto que el pensamiento de Locke facilita entender que la entrega de la voluntad y la libertad personal del sujeto no puede ser absoluta ya que, en tal caso, supondría de facto renunciar a la facultad de declararle la guerra cuando se muestre en desacuerdo. Por tanto, y para evitar tener que acudir al enfrentamiento como fórmula de discrepancia o a la renuncia al mismo, debe facilitarse que el sujeto pueda invocar de forma directa la defensa de tales derechos o impugnar judicialmente las leyes que coarten de forma natural y evidente su libertad o respecto de las que exprese discrepancia. Esa facultad debe ser independiente de la posibilidad de que se pueda articular una defensa adicional en las cámaras por las minorías parlamentarias y sin perjuicio de que éstas decidan o no efectuar dicha impugnación. Con esta fórmula se evitaría además las situaciones en las que el sujeto queda desasistido por dichas minorías, las cuales en definitiva no garantizan en modo alguno la autonomía ni la participación plena del individuo.

El segundo aspecto — dotar de contenido el vacío derecho de sufragio- supone aceptar que más allá de la mera participación que se realiza en los períodos electorales, el derecho de sufragio es un derecho estanco, carente de conexión con el haz que comprende los demás derechos fundamentales. Si la participación política resulta necesaria y el hombre ha de participar en el gobierno y obedecer las leyes que ayuda a elaborar, tal y como afirmaba Mably, esa participación ha de ser realmente efectiva y no limitada a la mera votación.

Para fomentar esa participación plena la solución tampoco se antoja tan sencilla, ya que no es posible que se realicen de forma continua las 
asambleas periódicas que proponía Rousseau, puesto que no es realista ni factible que una pregunta continua sea la mejor de las respuestas. Sin embargo, sí es razonable facilitar los mecanismos de reforma constitucionales de manera que en aquellos aspectos que atañan a las libertades y derechos fundamentales del sujeto, esa modificación se pueda efectuar de una forma más sencilla que la establecida en la mayoría de los sistemas existentes. Esa reforma simplificada, permite a su vez que, en caso de que se entienda que dicha reforma coarta los derechos del individuo, tales derechos puedan ser invocados mediante el sistema de impugnación directa al que nos referíamos anteriormente.

En todo caso, no parece que estas opciones resulten aplicables en el corto plazo, sobre todo en lo que respecta a la primera, ya que la defensa individual en lo que al ejercicio de los derechos fundamentales - sobre todo cuando se derivan de decisiones emanadas del poder legislativo- parece monopolizada por la acción política en una atribución en exceso colectiva y que reduce al sujeto a un mero espectador una vez deja caer su voto en la urna. Tal monopolio no deja de resultar irónico, por cuanto el poder legislativo busca en el poder judicial la respuesta a sus propios interrogantes, pese a que debiera mediar una aconsejable separación entre los mismos. Por otro lado, parece aceptable preguntarse hasta qué punto el poder legislativo puede resultar crítico consigo mismo y no caer en la autoindulgencia.

Quizás Locke y Rousseau eran más conscientes del futuro que de su propio presente.

\section{Referencias bibliográficas}

Álvarez Alonso, Clara. 1999. Lecciones de historia del constitucionalismo. Madrid: Marcial Pons.

Babeuf, Gracchus. 1988. Écrits. Presentés par Claude Mazauriac. Messidor: Éditions Sociales.

Barnave, Antoine. 1988. De la Révolution et de la Constitution. Grenoble: Presses Universitaires de Grenoble.

Bello, Eduardo. 1991. «El poder y los poderes en la Constitución de 1791». En Filosofía y Revolución, editado por Eduardo Bello, 35-76. Murcia: Universidad de Murcia, 35-76.

Bouloiseau, Marc. 1962. Le Comité de Salut Public. París: Presses Universitaires de France.

Código Civil de 1804. 1829. Le Code Civil, accompagné du texte annoté des lois qui ont abrogé ou modifié plusieurs de ses dispositions, et de l'indication de ser articles corrélatifs. Paris: Brissot-Thivars, Libraire Éditeur: 77. Acceso 
el 10 de febrero de 2020. https://gallica.bnf.fr/ark:/12148/bpt6k9659642v. $r=l e \% 20$ code $\% 20$ civil\%20brissot?rk=21459;2

Constitución francesa de 1791. 1834. Incluida en Lois, Décrets, Ordonannces. Réglemens, Avis du Conseil- D'état. Tome Troisième. J.B. Duvergier, 239257. París: A. Guyot. Acceso el 10 de febrero de 2020. https://gallica. bnf.fr/ark:/12148/bpt6k6512162r.r=lois\%2C\%20decrets \%2C\%20 ordonannces \%20tome\%20trosieme\%20par\%20j.b.duvergier?rk=257512;0

Constitución francesa de 1793. 1834. Incluida en Lois, Décrets, Ordonannces. Réglemens, Avis du Conseil- D'état. Tome Cinquiéme. J.B. Duvergier, 353-358. París: A. Guyot. Acceso el 10 de febrero de 2020. https:// gallica.bnf.fr/ark:/12148/bpt6k6510245z.r=lois\%2C\%20decrets\%2C\%20 ordonannces\%20tome\%20trosieme\%20par\%20j.b.duvergier?rk=21459;2

Cordero Quinzacara, Eduardo y Eduardo Aldunate Linaza. 2008. «Evolución histórica del concepto de propiedad». Revista de Estudios HistóricoJurídicos. Sección Historia del Pensamiento Jurídico, n. 30: 345-385.

Danton, Georges-Jacques. 1910. Discours. París: Societé de I'histoire de la Revolution Française.

Declaración de Derechos del Hombre y del Ciudadano de 1789. 1877. Incluida en Les Déclarations des Droits de L'Homme et du citoyen. 1789-17911793-1795, 4-7, París: Sandoz et Fischbacher. Acceso el 10 de febrero de 2020. https://gallica.bnf.fr/ark:/12148/bpt6k54716008/f7.image

Declaración de Derechos del Hombre y del Ciudadano de 1793. 1877. Incluida en Les Déclarations des Droits de L'Homme et du citoyen. 1789-17911793-1795. 8-12, París: Sandoz et Fischbacher. Acceso el 10 de febrero de 2020. https://gallica.bnf.fr/ark:/12148/bpt6k54716008/f7.image

Desmoulins, Camille. Les Révolutions de France et de Brabant. 1790. Número 3. París: Imprimerie Nationale : 97-143. Acceso el 10 de febrero de 2020. https://gallica.bnf.fr/ark:/12148/bpt6k10569186/f15.image

García de Enterría, Eduardo. 1986. Revolución Francesa y Administración Contemporánea. Madrid: Civitas.

Gauthier, Florence. 1992. Triomphe et mort du droit natural en Révolution 1789-1795-1802. París: Presses Universitaires de France.

Lefebvre, Georges. 1968. La Révolution Française. París: Presses Universitaires de France.

Locke, John. 1991. Dos ensayos sobre el gobierno civil. Madrid: Espasa Calpe.

Lucas Verdú, Pablo. 1991. "Proclamación, formulación y significado de la Declaración de Derechos del Hombre y del Ciudadano de 1789». Incluido en Derechos Humanos y Revolución Francesa, coordinado por Miguel Ángel García Herrera, 63-90. Bilbao: Universidad del País Vasco.

Mably, Gabriel de. 1865. Des droits et des devoirs du citoyen. París: Bureaux de la publication.

Marat, Jean Paul.1869. Oeuvres de J.P. Marat (L'Ami du Peuple). Recueillies et annoteés par A. Vermorel. París: Decembre- Alonnier. Libraire- Editeur.

Martin, Georges. 1963. Les Jacobins. París: Presses Universitaires de France. Montesquieu. 1987. El espíritu de las leyes. Madrid: Tecnos. 
Nicolás de Caritat, Marie Jean Antoine. 1847. Sur la liberté de la circulation des subsistances. París: Firmin Didot Fréres.

Nicolas de Caritat, Marie Jean Antoine. 1981. Journal d'instruction sociale par les citoyens Condorcet, Siéyes et Duhamel. París: Edhis.

Robespierre, Maximilien. 1866. Oeuvres de Robespierre. Recueillies et annoteés par A. Vermorel. París: F. Coernol.

Robespierre, Maximilien. 1840. Oeuvres de Maximilien Robespierre avec una notice historique, des notes et des commentaires par Laponneraye précédées de considérations générales par Armand Carrel. París: Analecta.

Robisco, Nathalie Barbara. 1998. Jean- Jacques Rousseau et la Révolution française. Une esthétique de la politique. 1792-1799. París: Honoré Champion.

Rodríguez Álvarez, Azucena. 1996. "Aproximación a la idea de «República» en la Francia Revolucionaria». Revista de Estudios Políticos (Nueva época), n. 91: 201-215.

Rousseau, Jean Jacques. 1988. El Contrato Social. Madrid: Tecnos.

Rousseau, Jean Jacques. 1923. Discurso sobre el origen de la desigualdad. Madrid: Calpe.

Sánchez Viamonte, Carlos. 1956. Los Derechos del Hombre en la Revolución Francesa. Méjico: Facultad de Derecho.

Soboul, Albert. 1979a. La Revolución Francesa. Madrid: Tecnos.

Soboul, Albert. 1979b. Les sans-culottes. París: Éditions du Seuil.

Tocqueville, Alexis. 1994. El Antiguo Régimen y la Revolución. Volumen 1. Madrid: Alianza.

Tomas y Valiente, Francisco. 1996. Constitución. Enciclopedia iberoamericana de filosofía. Filosofía Política II. Teoría del Estado. Madrid: Trotta.

Vovelle, Michel. 1981. Introducción a la historia de la Revolución Francesa. Barcelona: Crítica.

Zarka, Yves Charles. 2006. "Rousseau y la soberanía del pueblo». Derechos y libertades. n. 15, Época II, 47-63. 


\section{Copyright}

Deusto Journal of Human Rights / Revista Deusto de Derechos Humanos is an Open Access journal; which means that it is free for full and immediate access, reading, search, download, distribution, and reuse in any medium only for non-commercial purposes and in accordance with any applicable copyright legislation, without prior permission from the copyright holder (University of Deusto) or the author; provided the original work and publication source are properly cited (Issue number, year, pages and DOI if applicable) and any changes to the original are clearly indicated. Any other use of its content in any medium or format, now known or developed in the future, requires prior written permission of the copyright holder.

\section{Derechos de autoría}

Deusto Journal of Human Rights / Revista Deusto de Derechos Humanos es una revista de Acceso Abierto; lo que significa que es de libre acceso en su integridad inmediatamente después de la publicación de cada número. Se permite su lectura, la búsqueda, descarga, distribución y reutilización en cualquier tipo de soporte sólo para fines no comerciales y según lo previsto por la ley; sin la previa autorización de la Editorial (Universidad de Deusto) o la persona autora, siempre que la obra original sea debidamente citada (número, año, páginas y DOI si procede) y cualquier cambio en el original esté claramente indicado. Cualquier otro uso de su contenido en cualquier medio o formato, ahora conocido o desarrollado en el futuro, requiere el permiso previo por escrito de la persona titular de los derechos de autoría. 